\title{
EVALUASI WEBSITE SEKOLAH MENENGAH ATAS DI PROPINSI JAWA TIMUR DENGAN PENDEKATAN EVALUASI BERBASIS KONTEN
}

\author{
Suryo Adi Wibowo ${ }^{1}$, Yosep Agus Pranoto ${ }^{2}$, Kartiko Ardi Widodo ${ }^{3}$, Moh. Miftakhur Rokhman \\ ${ }^{1,2,4)}$ Teknik Informatika, Institut Teknologi Nasional Malang \\ ${ }^{3)}$ Teknik Elektro, Institut Teknologi Nasional Malang \\ oryusdee@gmail.com
}

\begin{abstract}
ABSTRAK
Semenjak ditemukanya internet sebagai salah satu media komunikasi dan informasi, website merupakan produk teknologi informasi yang terbilang paling populer, namun terkadang banyak website yang hadir tanpa kualitas yang bagus sehingga tidak dapat menyampaikan informasi yang dibawa. Kualitas sebuah website tentunya tergantung kepada pengujian dan pengawasan terhadap kualitas website itu sendiri, termasuk website sekolahsekolah di Indonesia. Jawa Timur adalah salah satu propinsi di Indonesia yang memiliki kuantitas dan kualitas pendidikan yang sangat baik baik ditingkat SD hingga SMA. Banyak sekolah di Jawa Timur yang masuk dalam Rintisan Sekolah Bertaraf Internasional meskipun kemudian kebijakan ini tidak dilanjutkan oleh pemerintah.

Website bagi sekolah adalah sarana untuk menyampaikan informasi kepada masyarakat dan juga sarana komunikasi yang pada era sekarang sangat banyak digemari karena efektivitas dan efisiensi dari teknologi website tersebut. Namun masih banyak ditemukan bahwa kualitas dan kuantitas informasi yang ada didalam konten website sekolah yang belum sepenuhnya dioptimalkan. Penelitian ini menggunakan beberpa kelompok parameter konten yang digunakan untuk evaluasi website sekolah. Diantaranya adalah informasi kontak, admisi, pemberdayaan alumni, profil, dan media sosial.

Hasil penelitian ini menunjukkan bahwa sekolah-sekolah yang ada di Jawa Timur sudah mulai menggunakan website sebagai sarana penyampaian informasi melalui media online. Namun berdasarkan parameter yang digunakan dalam penelitian ini, masih banyak ditemukan sekolah-sekolah yang belum mengoptimalkan website yang dimilikinya. Sebanyak 8,33\% sekolah yang benar-benar memanfaatkan konten informasi kontak yang jelas dan lengkap dalam websitenya, 2,98\% sekolah yang menyertakan informasi admisi, 7,15\% yang menampilkan profil alumni serta kegiatan alumni dalam websitenya, 27,68\% yang secara detail menyampaikan profil sekolah, serta hanya 2,08\% yang memanfaatkan tautan media sosial dalam website sekolahnya.
\end{abstract}

Keyword : evaluasi, website, sekolah, Jawa Timur

\section{PENDAHULUAN}

Hubungan antara sekolah dan masyarakat pada hakekatnya adalah suatu sarana yang cukup mempunyai peranan yang menentukan dalam rangka usaha mengadakan pembinaan pertumbuhan dan pengembangan murid-murid di sekolah. Secara umum orang dapat mengatakan apabila terjadi kontak, pertemuan dan lain-lain antara sekolah dengan orang di luar sekolah, adalah kegiatan hubungan sekolah dengan masyarakat. Hubungan antara sekolah dengan masyarakat khususnya wali murid atau orang tua dari siswa dapat terjadi dengan baik apabila keduanya melakukan komunikasi. Komunikasi dalam bahasa Ingris adalah communication, berasal dari kata commonicatio atau dari kata comunis yang berarti "sama" atau "sama maknanya" dengan kata lain komunikasi memberi pengertian bersama dengan maksud mengubah pikiran, sikap, perilaku, penerima dan melakukan yang diinginkan oleh komunikator. J.L. Aranguren dalam bukunya Human Communication (2011) menyatakan bahwa komunikasi adalah pengalihan komunikasi untuk memperoleh tanggapan.

Website sekolah merupakan salah satu alternatif penyampaian informasi (pengetahuan dan berita) berbasis Internet yang dikeluarkan oleh sekolah dengan tujuan untuk kemudahan dalam pendistribusian informasi pada publiknya, dalam hal ini adalah: siswa, orang tua siswa, dan masyarakat. Penyebaran informasi melalui website sekolah ini dilakukan atas kerjasama dari tenaga administrasiwebsite sekolah dengan humas sekolah, dengan penanggung jawab kepala sekolah. Selain untuk menyebarkan informasi berkenaan dengan profil sekolah, kegiatan sekolah, dan prestasi sekolah, kegunaan website sekolah juga dapat meningkatkan citra positif sekolah di mata publiknya. Publik yang dimaksud dalam hal ini adalah seluruh pihak yang melihat website sekolah dari Internet, seperti orang tua yang sedang mencari sekolah untuk anaknya, masyarakat pengguna pendidikan, ataupun ketika ada penawaran kerjasama dari suatu perguruan tinggi di luar negeri, pihak perguruan tinggi tersebut dapat dengan mudah melihat profil, kegiatan, dan prestasi sekolah melalui website sekolah, tanpa harus jauhjauh datang untuk observasi mengenai sekolah tersebut. Pemanfaatan website dan media sosial dapat mendorong efektivitas proses belajar dan mengajar di sekolah (Maqableh et. al., 2015).

Permasalahan umum yang terjadi pada website sekolah-sekolah di Indonesia adalah terkait dengan konten, baik dari segi kelengkapan konten dan waktu update konten yang lama. Hill dkk (2010) telah melakukan penelitian terkait evaluasi website sekolahsekolah di Southern California - Amerika Serikat dengan mengevaluasi konten website sekolah-sekolah 
tersebut. Hasil dari penelitian tersebut menunjukkan anya $50(17,5 \%)$ dari 285 sekolah yang diidentifikasi memiliki website yang aktif. Selain itu, sebagian besar website tidak memiliki konten yang lengkap. Dari hal tersebut, penulis tertarik untuk melihat seberapa baik website sekolah-sekolah di Jawa Timur ditinjau dari segi konten.

\section{METODE PENELITIAN}

\subsection{Tahapan Penelitian}

Tahapan penelitian ini terdiri dari lima tahapan, sebagai berikut :

1. Penentuan parameter penelitian.

2. Pencarian website sekolah-sekolah yang berada di kabupaten / kota di wilayah Jawa Timur, dengan beberapa ketentuan sebagai berikut:

a. Website dicari dengan menggunakan search engine Google dengan keyword tertentu yang mengandung kata ".sch.id"

b. Website sekolah yang dilibatkan dalam penelitian ini menggunakan domain ".sch.id"

c. URL berupa domain utama, tidak subdomain.

3. Penerapan parameter penilaian terhadap website sekolah-sekolah.

4. Collecting data penelitian.

5. Analisis dan pembahasan.

\subsection{Parameter penelitian.}

Parameter yang digunakan dalam kegiatan penelitian ini seperti yang tercantum dalam Tabel $1 \mathrm{di}$ bawah ini. Parameter ini mengadopsi dari penelitian yang dilakukan oleh Hill (2010).

\subsection{Website Sekolah}

Hasil pencarian menggunakan search engine Google didapatkan data sekolah seperti pada Tabel 2 di bawah ini.
Tabel 1. Parameter Penelitian

\begin{tabular}{|c|c|c|}
\hline No. & Parameter & $\begin{array}{l}\text { Kelompok } \\
\text { Parameter }\end{array}$ \\
\hline 1 & $\begin{array}{l}\text { Map / peta lokasi } \\
\text { sekolah }\end{array}$ & \multirow{3}{*}{ Informasi Kontak } \\
\hline 2 & $\begin{array}{l}\text { Informasi kontak } \\
\text { sekolah }\end{array}$ & \\
\hline 3 & $\begin{array}{l}\text { Alamat sekolah jelas } \\
\text { dan lengkap }\end{array}$ & \\
\hline 4 & $\begin{array}{l}\text { Penjelasan alur } \\
\text { proses pendaftaran }\end{array}$ & \multirow{3}{*}{ Admisi / PPDB } \\
\hline 5 & $\begin{array}{lr}\text { Informasi } & \text { jalur } \\
\text { penerimaan } & \text { siswa } \\
\text { baru } & \end{array}$ & \\
\hline 6 & $\begin{array}{l}\text { Kontak person untuk } \\
\text { panitia penerimaan } \\
\text { siswa baru }\end{array}$ & \\
\hline 7 & Informasi alumni & $\begin{array}{l}\text { Pemberdayaan } \\
\text { Alumni }\end{array}$ \\
\hline 8 & $\begin{array}{l}\text { Informasi profil } \\
\text { singkat sekolah }\end{array}$ & \multirow{7}{*}{ Profil Sekolah } \\
\hline 9 & $\begin{array}{l}\text { Informasi visi dan } \\
\text { misi sekolah }\end{array}$ & \\
\hline 10 & $\begin{array}{l}\begin{array}{l}\text { Informasi fasilitas } \\
\text { sekolah }\end{array} \\
\end{array}$ & \\
\hline 11 & $\begin{array}{l}\text { Informasi galeri foto / } \\
\text { video sekolah }\end{array}$ & \\
\hline 12 & $\begin{array}{l}\text { Informasi guru dan } \\
\text { staff sekolah }\end{array}$ & \\
\hline 13 & $\begin{array}{ll}\begin{array}{l}\text { Sambutan } \\
\text { sekolah }\end{array} & \text { kepala } \\
\end{array}$ & \\
\hline 14 & Berita terkini sekolah & \\
\hline 15 & Kategori berita & \\
\hline 16 & $\begin{array}{l}\text { Informasi berita } \\
\text { terpopuler }\end{array}$ & \\
\hline 17 & $\begin{array}{ll}\begin{array}{l}\text { Agenda } \\
\text { sekolah }\end{array} & \text { kegiatan } \\
\end{array}$ & \\
\hline 18 & $\begin{array}{ll}\begin{array}{l}\text { Informasi } \\
\text { sekolah }\end{array} & \text { prestasi } \\
\end{array}$ & \\
\hline 19 & Menu/area download & \\
\hline 20 & $\begin{array}{ll}\text { Informasi } & \text { statistik } \\
\text { pengunjung } & \end{array}$ & \\
\hline 21 & Polling & \\
\hline 22 & $\begin{array}{ll}\text { URL / Nama } \\
\text { Facebook }\end{array}$ & \multirow{3}{*}{ Media Sosial } \\
\hline 23 & URL / Nama Twitter & \\
\hline 24 & $\begin{array}{ll}\text { URL I Nama } \\
\text { Instagram }\end{array}$ & \\
\hline
\end{tabular}


Tabel 2. Data Sekolah yang diteliti.

\begin{tabular}{|c|c|c|c|}
\hline No. & Nama Sekolah & Kabupaten/Kota & Alamat Website \\
\hline 1 & SMAN 3 Blitar & Kota Blitar & https://sman3blitar.sch.id/ \\
\hline 2 & SMAN 2 Madiun & Kab Madiun & http://smanegeri2madiun.sch.id/ \\
\hline 3 & SMA Negeri 8 Malang & Kota Malang & http://www.sman8malang.sch.id/ \\
\hline 4 & SMA Negeri 4 Malang & Kota Malang & http://www.sman4malang.sch.id/ \\
\hline 5 & SMAN 21 Surabaya & Surabaya & https://sman21 surabaya.sch.id/ \\
\hline 6 & SMA Negeri 20 Surabaya & Surabaya & http://www.sman20surabaya.com \\
\hline 7 & SMAN 19 Surabaya & Surabaya & https://sman19sby.sch.id/ \\
\hline 8 & SMA Al Hikmah Surabaya & Surabaya & http://sma.alhikmahsby.sch.id/ \\
\hline 9 & SMAN 2 Genteng & Banyuwangi & https://www.sman2genteng.sch.id \\
\hline 10 & SMA Negeri 2 Jember & Jember & http://www.sman2jember.sch.id/ \\
\hline 11 & SMAN 1 Situbondo & Situbondo & https://www.sman1 situbondo.sch.id/ \\
\hline 12 & SMA Negeri 1 Krasakan & Kab Probolinggo & https://sman1kraksaan.sch.id/ \\
\hline 13 & SMA Negeri 1 Grati & Kab Pasuruan & http://sman1grati.sch.id/ \\
\hline 14 & SMA Negeri 2 Nganjuk & Kab Nganjuk & http://www.sman2nganjuk.sch.id/ \\
\hline 15 & SMA Negeri 1 Maospati & Kab Magetan & http://www.smanti.sch.id/ \\
\hline 16 & SMA Negeri 1 Magetan & Kab Magetan & http://www.smasa-magetan.sch.id/ \\
\hline 17 & SMA Negeri 1 Batu & Kota Batu & https://www.sman1batu.sch.id/ \\
\hline 18 & SMAN 1 Probolinggo & Kota Probolinggo & https://www.sman1probolinggo.sch.id/ \\
\hline 19 & SMA Negeri 2 Mojokerto & Kab Mojokerto & https://sman2mojokerto.sch.id/ \\
\hline 20 & SMA Negeri 1 Kediri & Kota Kediri & https://smastkediri.sch.id/ \\
\hline 21 & SMA Negeri 2 Surabaya & Surabaya & http://www.sman2-sby.sch.id/ \\
\hline 22 & SMAN 1 Sampang & Sampang & http://www.sman1sampang.sch.id/ \\
\hline 23 & SMA Negeri 1 Pamekasan & Pamekasan & http://www.sman1pmk.sch.id/ \\
\hline 24 & SMA Negeri 2 Bondowoso & Kab Bondowoso & http://sman2bondowoso.sch.id/ \\
\hline 25 & SMA Negeri 2 Lumajang & Kab Lumajang & http://www.sman2-lmj.sch.id/html/ \\
\hline 26 & SMA Negeri 1 Kepanjen & Kab Malang & http://smaneka.sch.id/ \\
\hline 27 & SMA Negeri 1 Trenggalek & Kab Trenggalek & http://sman1trenggalek.sch.id/ \\
\hline 28 & SMA Negeri 1 Boyolangu & Kab Tulungagung & https://sman1boyolangu.sch.id \\
\hline
\end{tabular}




\section{HASIL DAN PEMBAHASAN}

Setelah melakukan collecting data website sekolah-sekolah dengan menerapkan parameter yang telah ditentukan, maka langkah selanjutnya adalah menganalisis secara kuantitatif data tersebut. Pada Tabel 3 di bawah ini adalah hasil dari pengamatan pada website sekolah. Kolom Jml adalah kolom jumlah, yang didapatkan dari jumlah website sekolah yang telah mengimplementasikan tiap-tiap paremeter. Kolom Perc. adalah prosentase dari kolom jumlah dibagi degan total jumlah sekolah yang terlibat dalam penelitian. Sebagai contoh, parameter nomor 1, terdapat 3 sekolah yang telah menambahkan map/peta lokasi sekolah dalam websitenya.

Tabel 3. Hasil pengamatan website sekolah.

\begin{tabular}{|c|c|c|c|}
\hline No & Parameter & Jml & Perc. \\
\hline 1 & Map / peta lokasi sekolah & 3 & 10,72 \\
\hline 2 & Informasi kontak sekolah & 28 & 100 \\
\hline 3 & $\begin{array}{l}\text { Alamat sekolah jelas dan } \\
\text { lengkap }\end{array}$ & 25 & 89,29 \\
\hline 4 & $\begin{array}{l}\text { Penjelasan alur / proses } \\
\text { pendaftaran }\end{array}$ & 8 & 28,58 \\
\hline 5 & $\begin{array}{l}\text { Informasi jalur penerimaan } \\
\text { siswa baru }\end{array}$ & 10 & 35,72 \\
\hline 6 & $\begin{array}{l}\text { Kontak person untuk panitia } \\
\text { penerimaan siswa baru }\end{array}$ & 2 & 7,15 \\
\hline 7 & Informasi alumni & 2 & 7,15 \\
\hline 8 & $\begin{array}{l}\text { Informasi profil singkat } \\
\text { sekolah }\end{array}$ & 28 & 100 \\
\hline 9 & $\begin{array}{l}\text { Informasi visi dan misi } \\
\text { sekolah }\end{array}$ & 24 & 85,72 \\
\hline 10 & Informasi fasilitas sekolah & 18 & 64,29 \\
\hline 11 & $\begin{array}{l}\text { Informasi galeri foto / video } \\
\text { sekolah }\end{array}$ & 19 & 67,86 \\
\hline 12 & $\begin{array}{l}\text { Informasi guru dan staff } \\
\text { sekolah }\end{array}$ & 4 & 14,29 \\
\hline 13 & Sambutan kepala sekolah & 25 & 89,29 \\
\hline 14 & Berita terkini sekolah & 21 & 75 \\
\hline 15 & Kategori berita & 7 & 25 \\
\hline 16 & Informasi berita terpopuler & 3 & 10,72 \\
\hline 17 & Agenda kegiatan sekolah & 9 & 32,15 \\
\hline 18 & Informasi prestasi sekolah & 18 & 64,29 \\
\hline 19 & Menu/area download & 4 & 14,29 \\
\hline 20 & Informasi statistik pengunjung & 3 & 10,72 \\
\hline 21 & Polling & 3 & 10,72 \\
\hline 22 & $\begin{array}{l}\text { URL / Nama Facebook } \\
\text { Official }\end{array}$ & 9 & 32,15 \\
\hline 23 & URL / Nama Twitter Official & 2 & 7,15 \\
\hline 24 & $\begin{array}{l}\text { URL / Nama Instagram } \\
\text { Official }\end{array}$ & 3 & 10,72 \\
\hline
\end{tabular}

Hasil pengamatan pada Tabel 3 diatas jika dilakukan analisis berdasarkan kelompok parameter, maka dihasilkan data seperti yang tertera pada Tabel 4 di bawah ini.

Tabel 4. Hasil pengamatan berdasarkan kelompok parameter.

\begin{tabular}{|l|l|c|}
\hline No. & $\begin{array}{l}\text { Kelompok } \\
\text { Parameter }\end{array}$ & Presentase \\
\hline 1. & Informasi Kontak & 8,33 \\
\hline 2. & Admisi / PPDB & 2,98 \\
\hline 3. & $\begin{array}{l}\text { Pemberdayaan } \\
\text { Alumni }\end{array}$ & 7,15 \\
\hline 4. & Profil Sekolah & 27,68 \\
\hline 5. & Media Sosial & 2,08 \\
\hline & Total & 41,07 \\
\hline
\end{tabular}

Tabel 4 di atas menunjukkan bahwa sekolahsekolah di propinsi Jawa Timur masih belum mengoptimalkan potensi media website sebagai sarana komunikasi dengan publik. Total hanya $41,07 \%$ dari 28 sekolah yang telah menerapkan 24 parameter yang digunakan dalam penelitian ini.

\section{KESIMPULAN DAN SARAN}

\subsection{Kesimpulan}

Dari hasil penelitian ini, dapat disimpulkan sebagai berikut:

1) Sekolah-sekolah yang ada di Jawa Timur telah mulai menggunakan media website sebagai sarana publikasi kegiatan sekolah.

2) Sekolah-sekolah di Jawa Timur belum mengoptimalkan manfaat website sekolah yang dimilikinya.

3) Perlu adanya perbaikan konten yang ada di website sekolah-sekolah, sehingga masyarakat umum terbantu dengan adanya akses informasi yang lengkap.

\subsection{Saran}

Penelitian ini dapat diperdalam dengan menggunakan beberapa model evaluasi seperti usability dan accessibility.

\section{DAFTAR PUSTAKA}

[1]. Aranguren, JL, 2011. Human Communication Fourth Edition (Book 4). Mc Graw Hill. California

[2]. Hill, G.M. \& Tucker, M. \& Hannon, James. (2010). An evaluation of secondary school physical education websites. The Physical Educator. 67. 114-127.

[3]. Maqableh, M., Rajab, L., Quteshat, W., Masa'deh, R. E. M., Khatib, T., \& Karajeh, H. (2015). The impact of social media networks websites usage on students' academic performance. Communications and Network. 7. $159-171$ 